Island Studies Journal, Vol. 6, No. 1, 2011, pp. 45-58

\title{
"Sex and the Island": Lives of Single Women in Prince Edward Island
}

\author{
Kristie Collins \\ University of Tsukuba \\ Ibaraki-ken, Japan \\ kristiecollins@yahoo.com
}

\begin{abstract}
This article considers the significance attributed to Prince Edward Island in managing a marginalized single female identity, as presented by accounts of thirty nevermarried and previously-married Island women, aged twenty-seven through sixty-five. As popular media and social narratives overwhelmingly position contemporary single women against an urban backdrop, the question arises as to whether unmarried Island women feel "marooned" in ways their urban counterparts may not. In accordance with feminist aims to produce research for, rather than about, women's lives, the paper focuses on two themes from fieldwork interviews that were of particular interest to participants. The first theme relates to negotiating female singleness within the Island's familycentered culture, and the second theme presents participants' talk around advantages and disadvantages of living in Prince Edward Island, Canada, as single women. The paper concludes with a summary of other findings from the study and suggestions for future research on female singleness and island locales.
\end{abstract}

Keywords: female singleness, identity construction, island studies, lived experience, narrative, Prince Edward Island, stigma management

(C) 2011 Institute of Island Studies, University of Prince Edward Island, Canada

\section{Introduction}

On Prince Edward Island, I stayed in the pretty roadside house of old friends, not far from the shore. From my bedroom window I saw a white gibbous moon rolling in the deep blue summer sky, the moon of Artemis, the hunter, the solitary rider, the lady of wild things, the goddess who stands slightly outside society and makes her own rules ... The single women of Prince Edward Island move cautiously, discretely, within a grid of expectations as clear to them as the island's red roads. The term for somebody who thinks she's entitled to be different is "big feeling," as in "She's getting a bit big feeling." Like the goddess Artemis (Fraser, 2001: 81).

Mediated and real life experiences of single women have gained increasing attention in the global media in recent years, and the stories told have reflected substantial shifts in patterns of social organization and in the previously unchallenged script of the traditional, feminine life course. From the pioneering single girl portrayal of Mary Richards in The Mary Tyler Moore Show in the 1970s, to Carrie Bradshaw and her well-heeled friends in the contemporary Sex and the City franchise, single female characters have called into question the desirability and reliability of conventional heteronormative lifestyles, which 


\section{K. Collins}

entail an orderly progression from singlehood, to marital relationship, to motherhood. And yet, these mediated accounts of single women's lives are inevitably situated in urban American localities where central female characters are typically portrayed in highpaying, exciting work environments with ready access to inexhaustible dating pools drawn from colleagues, neighbours and friends. Relationships and sexual partners are often depicted as objects to be "consumed"-and disposed of - along with the material goods so often associated with the (mediated) urban single woman's lifestyle; like the brand name shoes and handbags so coveted on Sex and the City, each object of desire can easily be updated and improved upon each season.

As Fraser's (2008) opening excerpt suggests, however, the lives of single women in Prince Edward Island may not resemble popular mediated texts of female singleness. In fact, the thirty never-married and previously-married single Island women who participated in my doctoral research on media representations and lived experiences of single women revealed vastly variable experiences living, working, and dating in the capital city, small towns, and rural areas of Prince Edward Island. By lived experience, this paper refers to ongoing, shifting, and possibly contradictory experiences individuals engage with over their life courses - such as the construction and maintenance of marginalized social categories-rather than finite experiences containing defined beginnings and endings, as with, for instance, birthday parties or summer holidays (Byrne, 2003; Sharp \& Ganong, 2007). While respondents often identified with-and enjoyed - single female characters they saw in films and television, few of them felt these representations offered "accurate" portrayals of their own experiences as single women living on the Island". For instance, although most participants supported single characters' rights to consume goods and services (and men) at their leisure, most of the participants had limited disposable income to draw upon, and the bulk of their financial resources went to supporting children, reducing personal debt, or enjoying low-key/lowcost socializing with friends - a stark contrast to the upscale martini bars frequented by women in Sex and the City. As for the lucrative careers and infinite dating pools that are the constant backdrop of the mediated single woman's life, the reality for the Prince Edward Island residents was rather more modest.

Instead, participants' narratives focused closely on the challenges of negotiating "respectable" social identities as single women living in non-urban and small provincial city locales, a complex balancing act that incorporated the perceived advantages of autonomy and self-sufficiency in the organization of their lives as independent modern women - the hegemonic social construction of contemporary female singleness - with the difficulty of seeing themselves perceived, socially, as having failed in following the normative path of life-long marriage and motherhood, the traditional script which remains privileged in Island society. Consequently, a polarization could be detected between contemporary social constructions of mediated single women and the specificity of single women's experiences on Prince Edward Island. ${ }^{2}$

\footnotetext{
1 "Prince Edward Island" and "the Island" are used interchangeably throughout the article as many residents refer to Prince Edward Island simply as "the Island."

${ }^{2}$ For more discussion on shifts in media representations of single women, see Collins (2008a; 2007). For further analysis of lived experiences of female singleness over the life course, see Collins (2009b; 2008b).
} 
This article examines the particular significance attributed to Prince Edward Island as a distinct locality in managing marginalized single female identity as presented in accounts by thirty never-married and previously-married female Island participants aged twentyseven to sixty-five. After providing an overview of the research study background and the participant profiles, the paper focuses on two dominant themes that emerged from one-toone interviews. The first theme relates to issues arising from negotiating female singleness within the Island's family-centered culture; while the second theme presents participants' talk around advantages and disadvantages of living in Prince Edward Island as single women. The paper concludes with a summary of other key findings from the study and suggestions for future research on female singleness and island localities.

\section{Research study background}

The interviews discussed in this paper are taken from fieldwork conducted in the summer of 2006 (Collins, 2009a). The decision was made to focus upon single women and self/social identity construction in Prince Edward Island, as this location provided a contrast to urban contexts so regularly associated with female singleness in the media. This approach therefore offered rich insights into the lives of single women in localities previously overlooked by most singleness researchers. As the study aimed to shed light on how previously-married and never-married single women "made sense" of their singleness at different stages of the life course, a priority was to find an assortment of never-married, divorced, separated, and widowed women across defined age groups to participate in the fieldwork.

Participants were made aware of the study through recruitment fliers, notices and news stories in local media outlets, and through the use of the "snowball technique" (Mason, 2002) which draws upon friends and colleagues to assist in gathering suitable candidates from their own social and professional networks. Fortunately, a satisfactory balance was achieved for the study, eliciting the desired number of volunteers for the (non)marital groups and age cohort groups, with sixteen participants being never-married singles and fourteen participants having been previously married. Eleven women were over the age of fifty, eight women were in their forties, and another eleven women were aged thirtynine or under. The breakdown of participant age and (non)marital status is detailed in Table 1.

All participants were white/Caucasian, and the majority came from middle class or upwardly mobile, working class backgrounds. Seven were raised outside Prince Edward Island and relocated to the province as adults. While nearly half of those "born and bred on the Island" lived away from the Island for several years for education or work, these women are still considered "Islanders" in ways that women who moved to the province are not, and this status positions them differently in Island society. Regarding sexual orientation, although some participants did not refer to an inherently heterosexual orientation - or to any orientation at all —none of the women self-identified as lesbian. One participant has been separated from her spouse for more than a decade but remains unable to afford the expense of legally divorcing him; and two were in monogamous 


\section{K. Collins}

relationships with men (without cohabiting) but still self-defined as single women. Finally, all of the participants were able-bodied, and the few women who lived with family members (their own children or with their parents for care-taking or cost-saving measures) claimed to do so by choice.

\section{Table 1: Participant Age and (Non)Marital Status}

\begin{tabular}{|c|c|c|}
\hline $\begin{array}{c}\text { Participant age and } \\
\text { (non)marital status }\end{array}$ & $\begin{array}{c}\text { Never-married participants } \\
(16)\end{array}$ & $\begin{array}{c}\text { Previously-married } \\
\text { participants (14) }\end{array}$ \\
\hline $\begin{array}{c}50 \text { to } 65 \text { years old } \\
\text { (11 participants) }\end{array}$ & 4 & 7 \\
\hline $\begin{array}{c}40 \text { to } 49 \text { years old } \\
\text { (8 participants) }\end{array}$ & 4 & 4 \\
\hline $\begin{array}{c}\text { (11 to } 39 \text { yearticipants) } \\
\text { (11) }\end{array}$ & 8 & 3 \\
\hline
\end{tabular}

In accordance with feminist objectives that aim to empower women through applied feminist studies and to eradicate the traditional imbalance of power between researcher and participant, attempts were made to include participants in various stages of the research process. As Longino (1993: 101) explains, feminist epistemologies in the social sciences strive to:

[design] research for rather than merely about women, a goal that requires attending to the specification of women's lives and consulting research subjects themselves about the process of gathering information about them.

Thus, the design of the fieldwork was organized to allow for input and reflexivity from the participants in several ways.

First, prior to the one-to-one interviews, participants met in focus groups to discuss and clarify their thoughts on their identities as single women both collectively and individually. Many later expressed gratitude to have met other single women who understood their feelings of ambiguity over their shared non(marital) status. Several participants then used interview time to rephrase or elaborate on contributions they had made in earlier focus group discussions; the opportunity to reflect on their thoughts after the focus groups and, subsequently, to express their ideas again in the one-to-one interviews, seemed cathartic for many. Finally, two months after the interviews were concluded, all participants were invited to attend an informal talk and reception where preliminary findings from the study were presented. This stage proved to be a wonderful opportunity for participants across different age cohort and (non)marital status groups to converse about singleness, and for the women to get a sense of their roles and vital inputs 
in the larger design of the project. As recently as this past week-years after the completion of the fieldwork - I have received emails from women who participated in the study, asking to be put in touch with other participants and simply wishing me well with my research. Their participation and support has been invaluable to my research, and the results produced from the study resonate with the chorus of their voices as they share their hopes, fears, frustrations and dreams as single, Prince Edward Island women.

\section{"It's a family place..."}

Time and again, the phrase "it's a family place" surfaced in interviews as a way of describing Prince Edward Island - in equal measure a critique and a point of pride among participants. For many, local kin networks were the primary reason for having stayed on - or relocated to - the Island. Unavoidably, however, this family-centered perception of Island society creates an ambiguous climate for many unmarried and/or childless women who reported feeling "conspicuously single" in a familial culture that privileges marital relationships (Byrne \& Carr, 2003). Elizabeth Gilbert, author of the bestselling novel Eat, Pray, Love, aptly describes the complex negotiation undertaken by singles as they attempt to position themselves within the family-centric culture:

To create a family with a spouse is one of the most fundamental ways a person can find continuity and meaning in American (or any) society. I rediscover this truth every time I go to a big reunion of my mother's family in Minnesota and I see how everyone is held so reassuringly in their positions over the years. First you are a child, then you are a teenager, then you are a young married person, then you are a parent, then you are retired, then you are a grandparent - at every stage you know who you are, you know what your duty is and you know where to sit at the reunion... But what if, either by choice or by reluctant necessity, you end up not participating in this comforting cycle of family and continuity? What if you step out? Where do you sit at the reunion? (Gilbert, 2006: 94-95).

This sense of having "stepped out" of the heteronormative life course was a key point in the interviews and many participants insisted that the pressure to be married (or to be not single, at least) in Prince Edward Island was stronger than it would be elsewhere-in no small part due to the Island's collective espousal of the Ideology of Marriage and Family (Byrne \& Carr, 2003). This ideology upholds the notion that married individuals are happier and healthier than their single counterparts, and while this belief holds sway throughout North American society, it remains a particularly powerful discourse in nonurban areas and is a prevalent concept in Island society. The privileging of family and marital roles is made apparent in commercial, social, and media discourse of everyday Island life. From provincial tourism campaigns promoting the Island's family-friendly ways, to the celebrated "Old Home Week" carnival that summons off-Islanders home to reunite with their families each summer, to the local newspaper's prominent display of engagement, wedding and birth announcements, the significance attributed to family and marital roles is pervasive in Prince Edward Island life. 


\section{K. Collins}

It is important to note that many of the respondents questioned the notion that taking on marital and parental roles would necessarily lead one to greater health and happiness. However, most were keenly aware that those around them viewed their non-participation in the conventional feminine life course as "abnormal". As many scholars have observed (e.g. Baldacchino, 1997, 2005, 2006; Barnes, 1954; Marshall \& Foster, 2002), the small size and scale of island localities can be likened to a "straight-jacket of community surveillance" (Weale, 1992: 9), in which social expectations (such as marriage and parenting) are more readily monitored - a sort of "screening" practice experienced by many participants in the study. Thus, due to the distinctive borders of water that determine our geographic boundaries (Hay, 2006), one can easily envision the single Island women who stray from this elected path as feeling "marooned" in a way that their urban counterparts are unlikely to feel in their largely anonymous city lives.

The challenges faced by single Island women in managing their social identities was also noted by Marion Botsford Fraser, who wrote in her nationwide study of single Canadian women that:

single women are oddities in Prince Edward Island, I was told. Leaving a husband, not marrying at all, having a marginally bohemian lifestyle takes courage (Fraser, 2001:81).

The women in my study frequently reiterated this observation, suggesting that singleness, and particularly female singleness, continues to be held in low esteem on the Island. Although they acknowledged that female singleness would be problematic to negotiate elsewhere, they were adamant that their (non)marital status was under even closer scrutiny as a result of living in Prince Edward Island where anonymity is difficult to find. For some participants, the negative evaluation of their single status was observed in passing comments from neighbours who were overly-vigilant in monitoring the comings and goings of the single women's houseguests. For others, it was self-imposed by their refusal to enter places and spaces where they felt conspicuously alone, such as cinemas or restaurants, activities most women admitted they could undertake on their own when offIsland. In other words, whereas city singles are seen to be able to blend into their environments relatively easily_as apartment dwelling, commuter schedules, and social networking allow urban singles and partnered individuals to co-exist without much outward differentiation - non-urban singles may be viewed as oddities in communities that revolve around family life, and where women are expected to, eventually, marry and raise families. Furthermore, whereas urban singles would rarely have unexpected encounters with family, friends or acquaintances due to the size and scope of their city locales, Islanders need to:

... learn to get along, like it or not, with one another, knowing that they are likely to renew and reinforce relationships with the same persons in a variety of contexts over a whole lifespan (Baldacchino, 1997:77). 
This need to "get along" with other Islanders often seems to come at a high price for the single women with whom I worked. As an example of this pressure to conform to social norms, some participants told stories of being compelled to justify or defend their singleness to family members who lived locally, a situation which seemed particularly common amongst the never-married women over the age of forty. It also seemed to be an issue that was more frequently raised by participants living in small towns and rural areas where single women seemed to be viewed as somewhat "odd" or as threatening to social conventions. This negative evaluation connects to an idealization of traditional femininity - which inevitably entails marriage and motherhood - an ideal that is still privileged in most (post)traditional, non-urban communities. "Bonnie" ${ }^{3}$, a thoughtful, 52 year-old, never-married participant, recalled the harassment she suffered at family reunions in her thirties and forties:

B: These [were] old relatives, people of my parents' generation... the ones who used to point [my singleness] out... it was kind of a-I think - a sport for them, and just to see what I would say. And I did have one aunt who, apparently, used to hold a belief that if you were not married, you just didn't count.

In fact, many participants at some point had been required by those around them to account for their single status; in interviews they expressed frustration at the shortage of socially acceptable explanations that seemed to position them as having any sense of personal agency in their singleness. Instead, as the fictional single heroine of Bridget Jones's Diary (2001) wittily responds when asked why so many of the "office girls" were remaining single:

Well, I suppose it doesn't help that, underneath our clothes, we're all covered in scales.

Although this remark is said in jest, the underlying sense that some hidden flaw is responsible for women's singleness still seems to be commonly held, and functions by disallowing the possibility of women choosing singleness. As a result, participants are made to negotiate narratives of being "single by choice" or "single by chance". This presents:

... an ideological dilemma as to how to negotiate this agentic self while dealing with trouble in the form of inconsistency or discomfort in the different subject positions taken up (Reynolds et al., 2007: 348).

On the one hand, the women could opt to position themselves as disinterested in partnering and parenting, but employing this strategy risks the chance of being perceived socially as "abnormal" in their needs and desires. On the other hand, they could position themselves as hopeful that a romantic relationship would develop in the future, but the notion of needing to wait for suitable and eligible partners to present themselves limits each woman's sense of agency and self-control. In either case, single women are left with

\footnotetext{
${ }^{3}$ Names and identifying details have been changed throughout the article in order to protect the privacy of the project participants.
} 


\section{K. Collins}

unsatisfactory resources to draw upon in presenting their lives to others as chosen and "respectable."

Nevertheless, many participants rebuffed this dated misconception of (female) singleness as consolation status and had consciously chosen their singleness or now prefer their single status. This resolution was especially true for older participants who, having already passed an internalized and individualized age deadline for marriage, now identified closely with being single (Davies, 2003). In fact, as participants moved further away from the statistically standard age of first marriage-when social pressure over marital status is strongest - they were more able to identify advantages that accompanied the single lifestyle. As the successful, never-married "Jeanne" explains:

J: I likely at one point thought I'd like to be married, but I think once you get over-like, for me, it was once I got to thirty-I thought: "God, I like this lifestyle."

Many of the participants, particularly those in the over-40 and over-50 age cohort groups, shared Jeanne's sense of satisfaction with their single lifestyles. According to the women, some advantages of staying or becoming single included financial independence, better schedule flexibility, increased time for hobbies and socializing, and opportunities to travel or relocate as they so choose. In summary, while difficulties relating to identity construction and maintenance could be observed in making singleness "understandable" and "acceptable" to those around them, it was evident from interviews that the women recognized benefits in their (non)marital status, particularly as they moved forward in the life course.

\section{"Do you want the high-paying job in Toronto or do you want a life?"}

At the close of each interview, participants were asked to share their reasons for choosing to live in Prince Edward Island and their perceptions of the advantages and disadvantages of being single in that specific locality. They were also invited to explain whether or not they would recommend Prince Edward Island to other single women who might be considering a move to the Island. Some responses given for living on the Island included the desire to be near family, the sense of security and safety that was particularly valued by women living alone, and the low cost of living that afforded them the option to own their own homes. As previously-married participant "Betty" noted on the topic of Prince Edward Island real estate:

B: Well, I'm spending on a house what I spent on a one bedroom apartment in Toronto.

Home ownership and short commutes to work ranked high as advantages to living on the Island, while lack of privacy and the (perceived) shortage of desirable romantic partners were offered as some of the disadvantages. And while most participants expressed an intention to remain on the Island in the future, few of them felt they would recommend it to other single women-partly, some said with a smile, because they did not want the 
added "competition." In truth, however, the women seemed to place high value on their relationships with other women, both married and single. One even went so far as to say that the support and companionship of the (single) female community should be seen as a primary reason for single women to consider a move to the Island.

The Island's population size and relatively slow pace of life were simultaneously seen by the participants to be its strongest and weakest selling points. For the under-40, nevermarried cohort group, the isolation of the Island locality was viewed as an obstacle in terms of career advancement and opportunities to meet suitable partners. Conversely, the mythical image of the friendly, idyllic Island was readily embraced by participants who expressed the desire to raise their children in a close-knit community where a slower pace of life was equated with a safer and gentler childhood. Of the thirty participants, ten previously-married and three never-married women had children, and they were unanimous in having made a conscious decision to raise their families in Prince Edward Island. While several were already living on the Island when earlier relationships ended, and then chose to stay and raise their children on their own, others had previously relocated off-Island and found the challenge of single parenting motivated them to return to cherished support networks of family and friends. "Olivia", a 53 year-old, previouslymarried participant, recounts the turning point, which influenced her to return from British Columbia with her daughter:

O: [W]hen I lived in British Columbia, when she was an infant, I used to have to travel on buses, of course. I remember coming back through West Vancouver at the end of a school day and we went by an elementary school. And they picked up the students. And I'm looking at these girls getting on - now they're in Grade 6-and they've got belly shirts on, and they've got heavy makeup on, and they've got their hair up every which way, and they're talking about things I didn't talk about in Grade 6. And I just thought to myself, there's no way I can stay here. Because [my daughter] cannot grow up like that. I've got to take her home. And let her grow up slow.

Responses from participants shed light on various positive and negative implications of living as single women in Prince Edward Island, and significant differences emerged between the narratives of women who were born and raised on the Island and those who had moved there as adults. In an earlier study on elderly, never-married single Prince Edward Island women, O'Brien (1991) reported that these women had a high degree of life satisfaction and independence, a conclusion largely supported in my own research. Her study also suggested that their social networks were predominantly comprised of kin relations and similarly aged friends. This finding raises concerns as to how women-or men, for that matter-fare in establishing social support systems on the Island without kin networks in place. In fact, many of the participants who had relocated to the Island mid-career recalled experiencing struggles in social networking, initially, a challenge also noted by Baldacchino (2006) in his report on recent immigrants to Prince Edward Island. In time, most of the women said that they had been able to establish friendships through work or through group memberships, but it seems noteworthy that, at the time of the 


\section{K. Collins}

interviews, only two of the seven participants from "off-Island" indicated a desire to stay on the Island permanently.

In contrast to the seven participants who came to Prince Edward Island from "away"and the thirteen who had never left - are insights from ten who left the Island and chose to return. While some who had never lived off-Island struggled in narratives to "own" their choice in having had continuous residence on the Island (much the same way that the narratives indicated difficulty in participants "owning" their singleness), "return" participants were able comfortably to position themselves as having "chosen" to live on the Island. For "Betty", returning to Prince Edward Island after decades of moving around Canada provided her with a much longed-for sense of home. Betty's surname is considered "old Island stock", which allowed her easy access to Island networks and a comprehensible social identity. ${ }^{4}$ When asked if she would advise other single women to relocate to the Island, she immediately drew attention to the significance of kin relations and to the advantages and disadvantages of being connected - and known - by the Island community at large:

B: Life is real here, just like it's real every place else. It's just that people know a lot more about you than they would anyplace else. So, I mean it's really spooky, it doesn't matter how long you've been gone, I met one elderly lady on the street one day and made some comment about being stubborn and she goes, "you're from the [Cameron] and the [Stewart] side of the [Campbell] family, aren't you?" and I was like, "wo... she just said my grandmother and grandfather's sidesshe's right!" That's the scary part... [P] eople know about you, and people work around it-I have never seen such gossip in my life! So, when you're living in a bigger centre, there's more anonymity which you don't have here. And it has its good sides and its bad sides. But be prepared for it.

Many of the other "return" women had worked, studied, or lived in urban centres so often associated with the single, female experience, but said that they found the cities lacking in the "authenticity" they most associated with, and appreciated about, Prince Edward Island. "Audrey," who shuttled between Toronto and the Island for most of her life, explains how ultimately she chose to settle in Charlottetown for her own spiritual and physical well being, selecting the Island's "quality of life" over the material comforts of the city:

A: Oh yeah, I chose that a long time ago. That was coming since I was a kid, you know, I was born here, spent the first three years of my life here, and then started moving around. And ended up having to come back and stay here for years at a time... And as the big city got bigger and dirtier, this place got more attractive. [It came down to] do you want the high-paying job in Toronto or do you want a life?

\footnotetext{
${ }^{4}$ For many Islanders, making sense of one's social identity is done primarily through establishing their connections to other Island families and communities-genealogical resources and reference points unavailable to those "from away". For further discussion, see Baldacchino (2006) and Collins (2009a).
} 
It may be determined from participants' responses that they perceived their lives as single women on the Island as having both positive and negative outcomes. Living in Prince Edward Island meant the women were able to afford accommodations cheaper that those elsewhere and in urban locations, to shorten work commutes, and to enjoy the unspoiled nature of the Island; from a social networking point of view, however, opportunities to interact with other singles were said to be in short supply, and complaints were made about the general lack of privacy and the outdated "policing" they observed in relation to female sexuality.

\section{Conclusion}

A significant and previously under-researched factor in the study of lived experiences, and perceptions, of single women has been the spaces and places in which they live and interact with others. Contemporary media representations and academic studies alike presume singles reside exclusively in urban settings and often attribute their singleness to long work hours and the effects of living in post-traditional, disjointed communities. In fact, many single-centered television series about women unfold without any mention of family members, and the communities within which the single characters interact are often organized solely around friends, co-workers, and romantic interests. This mediated construction of single women in the city, however, does not accurately reflect the accounts of women interviewed for this study. Instead, their narratives revealed a deep interconnectedness amongst Prince Edward Island residents, and a variety of issues from the role of kin networks, to limited career opportunities on the Island, to a scarcity of local social venues became key factors in making sense of their lives as single women living outside the "typical" (read "urban") setting. Time and time again, the women asserted that female singleness was constructed differently on the Island —often a point of contention for participants born and raised elsewhere and who now found themselves confronting social constructions they viewed as outdated. According to Jarviluoma et al. (2003:14), however, locality is inextricably woven into the performance of social categories such as gender:

Gender, like other cultural categories such as ethnicity and sexuality, is performed differently in different situations and locations. Gender performance, like any performance of other cultural categories, takes place as a negotiation between context-bound and situational subjects.

It seems clear from participants' experiences of negotiating singleness in Prince Edward Island that geographic localities do play significant roles in the way that marginalized social identities - such as the single female identity — are constructed and maintained. And while social and institutional changes are taking place in Prince Edward Island just as they are elsewhere, traditional life course transitions such as (heterosexual) marriage and parenthood continue to play pivotal roles in structuring the lives of Island residents, problematically positioning unmarried individuals on the margins. Clearly, participants appreciated many aspects of their lives as single women on the Island, citing affordable housing, safe communities and kin networks as valued parts of their lives. A sense of 


\section{K. Collins}

community surveillance, however, was strongly resented and was attributed to the small size of the Island's social field (Baldacchino, 1997).

It would be of great value therefore to extend this study and pursue work in other Island localities to examine whether similar results are found in the ways in which single women do identity work and stigma management elsewhere. In placing "Island locality" at the centre of the academic terrain on female singleness, we can challenge the assumption of singleness being a purely urban experience, and offer the alternative tale of Sex and the Island.

\section{References}

Baldacchino, G. (1997) Global Tourism \& Informal Labour Relations: The Small-scale Syndrome at Work, London, Mansell.

Baldacchino, G. (2005) "The Contribution of "Social Capital" to Economic Growth: Lessons from Island Jurisdictions', The Round Table, Vol. 94, Issue 378, pp. 31-46.

Baldacchino, G. (2006) Coming to, and Settling on, Prince Edward Island: Stories and Voices: A Report on a Study of Recent Immigrants to PEI, Charlottetown, Canada, University of Prince Edward Island with the support of the Population Secretariat, PEI Provincial Government. www.islandstudies.ca/sites/vre2.upei.ca.islandstudies.ca/files/u2/Settlers to PEI.pdf.

Barnes, J. (1954) 'Class and Committees in a Norwegian Island Parish', Human Relations, Vol. 7, No. 1, pp. 39-58.

Byrne, A. (2003) 'Developing a Sociological Model for Researching Women's Self and Social Identities', European Journal of Women's Studies, Vol. 10, No. 4, pp. 443-464.

Byrne, A. \& D. Carr (2005) 'Caught in the Cultural Lag: The Stigma of Singlehood', Psychological Enquiry, Vol. 16, Nos. 2\&3, pp. 84-91.

Collins, K. (2009a) 'The Marginalized Majority: Media Representations and Lived Experiences of Single Women' unpublished $\mathrm{PhD}$ dissertation, Japan, University of Tsukuba, 274pp.

Collins, K. (2009b) 'Prince Edward Island Women's Experiences of Singleness: a Life Course Perspective', Canada Project in Kyushu Colloquium, Canada Project of the Institute for Regional Studies at The International University of Kagoshima, Japan, Vol. 5, pp. 7-12.

Collins, K. (2008a) 'Representations of Single Women in American Television: Shifting positions of femininity from The Mary Tyler Moore Show to Sex and the City', Studies in Comparative Culture, College of Comparative Culture, University of Tsukuba, Japan, No. 4, pp. 43-50. 
Collins, K. (2008b) 'Singular Lives: Interviews with three decades of previously-married and never-married single, Prince Edward Island Women', Canada Project in Kyushu Colloquium, Canada Project of the Institute for Regional Studies at The International University of Kagoshima, Japan, Vol. 3, pp. 43-50.

Collins, K. (2007) 'From Mary to Carrie: 30 Years of Media Representations and Lived Experiences of Single Women' in K. Kolarova and V. Sokolova (eds.) Gender and Generation, Prague, Literraria Pragensia, pp. 170-188.

Davies, L. (2003) 'Singlehood: Transitions within a Gendered World', Canadian Journal on Aging, Vol. 22, No. 4, pp. 343-352.

Fraser, M. B. (2001) Solitaire: The Intimate Lives of Single Women, Toronto, Macfarlane Walter \& Ross.

Gilbert, E. (2006) Eat, Pray, Love, New York, Viking.

Hay, P. (2006) 'A Phenomenology of Islands', Island Studies Journal, Vol. 1, No. 1, pp. $19-42$.

Jarviluoma, H., Moisala, P. \& A. Vilkko. (2003) Gender and Qualitative Methods, London, Sage.

Longino, H. E. (1993) 'Subjects, Power and Knowledge: Description and Prescription in Feminist Philosophies of Science' in L. Alcoff and E. Potter (eds.) Feminist Epistemologies, London, Routledge, pp. 101-120.

Marshall, J. \& N. Foster (2002) "“Between Belonging”: Habitus and the Migration Experience", The Canadian Geographer, Vol. 46, No. 1, pp. 63-83.

Mason, J. (2002) Qualitative Researching, $2^{\text {nd }}$ edition, London, Sage.

O’Brien, M. (1991) 'Never Married Older Women: The Life Experience', Social Indicators Research, Vol. 24, No. 2, pp. 301-315.

Reynolds, J., Wetherell, M. \& S. Taylor (2007) 'Choice and Chance: Negotiating Agency in Narratives of Singleness', The Sociological Review, Vol. 55, No. 2, pp. 331-351.

Sharp, E. \& L. Ganong (2007) 'Living in the Gray: Women's Experiences of Missing the Marital Transition', Journal of Marriage and Family, Vol. 69 (August), pp. 831-844.

Weale, D. (1992) Them Times, Charlottetown, Canada, Island Studies Press. 


\section{K. Collins}

\section{Movies and Television Series}

Bridget Jones's Diary. Feature Film. Directed by Sharon Maguire. 2001. UK/France: Little Bird.

Sex and the City. Television Series. Created by Darren Star. USA: Home Box Office (HBO), 1998-2004.

The Mary Tyler Moore Show. Television Series. Created by James L. Brooks and Alan Burns. USA: Columbia Broadcasting System (CBS), 1970-1977. 